\title{
Adoption of business analytics and impact on performance: A qualitative study in retail
}

\author{
Authors: \\ Ramakrishnan Ramanathan, Elly Philpott ${ }^{1}$, Yanqing Duan and Guangming Cao \\ Business and Management Research Institute, University of Bedfordshire, Luton, \\ UK
}

\begin{abstract}
This paper describes a qualitative study aimed at understanding issues faced by retail firms when they start a project of implementing Business Analytics (BA) and understanding the impact of BA implementation on business performance. Our study is informed by prior literature and the theoretical perspectives of the Technology-Organisation-Environment (TOE) framework but is not constrained by this theory. Using case studies of nine retailers in the UK, we have found support for the link between TOE elements and adoption. In addition, we have identified more interesting involvement of additional factors in ensuring how firms could maximise benefit derived from BA and traditional TOE factors that potentially could have additional impacts different from the ones. For example, there appears a link between adoption of BA and business performance (including performance in terms of environmental sustainability), and this link is moderated by the level of BA adoption, IT integration and trust.
\end{abstract}

Key Words: Business Analytics, Adoption, TOE framework, Business performance

\section{Introduction}

Business Analytics (BA) is overhauling the way firms are generating and using data worldwide (Dubey and Gunasekaran, 2015; Oberg and Graham, 2016; Wamba et al., 2015; Waller and Fawcett, 2013). BA is broadly defined in the literature as "the techniques, technologies,

\footnotetext{
${ }^{1}$ Present position: Higher Education Quality Manager with the Chartered Management Institute.
} 
systems, practices, methodologies, and applications that analyse critical business data to help an enterprise better understand its business and market and make timely business decisions" (Chen et al., 2012, p. 1166). While there have been several efforts on the development of BA tools and techniques, there are fewer academic studies that understand how BA is impacting businesses. Specifically, there is a need for further understanding of the issues faced by businesses when they embark on a project to invest in BA (Hazen et al., 2014). In this study, we aim to understand important factors to be considered by a firm for successful adoption of BA. We further explore the link between these factors and business performance.

This research focuses on the retail sector in the UK. This choice is dictated by several reasons. It is the eighth biggest sector of the world economy in terms of total market value and accounts for $7 \%$ of total value-added (Hristov and Reynolds, 2007). The retail sector is often considered at the forefront of using BA tools because of its emphasis on understanding customers better (e.g., Hübner and Kuhn, 2012). As a result, of all the business sectors, BA seems to have been well used by the retail sector (e.g., Google analytics and loyalty schemes by Tesco and other retailers; Ghoniem and Maddah, 2015). Despite a number of high profile cases of successful implementation (e.g. Tesco) and less successful implementation (e.g. Halfords) of BA, literature has yet to reflect an in-depth theoretical abridgement between practice and theory and few empirical cases are available on which to develop or test theories.

The UK context is also important. The retail sector employs about $10 \%$ of the UK's working population. As per data from the British Retail Consortium (BRC, 2012), retail sales in the UK were over $£ 303$ billion in 2011. More than a third of consumer spending goes through shops. More importantly to the context of BA, the value of Internet sales was $£ 27$ billion, accounting for around $9 \%$ of total retail sales. The UK retail sector is therefore a very attractive unit of analysis especially as it directly accounts for over $5 \%$ of UK GDP, employs one in nine of the workforce, and is the sixth largest retail market in the world by sales (HM Government, 2011). 
Hence, it is argued that the ability therefore to effectively model the implementation and effects of BA will be of enormous use to practitioners and academics alike.

Thus this study focuses on the UK retail sector to understand factors to be considered by a firm for successful adoption of BA. Though there are studies in the Information Systems literature (e.g., Johnson, 1999; Krause et al., 1998; Ashurst et al., 2012; Reinmoeller and Ansari, 2015) that explored the impact of IT investments on performance of firms, studies on the impact of BA are relatively recent and there is still little empirical evidence to understand factors for successful adoption of BA and improve firm performance.

We attempt to fill this important research gap in this paper. Our study attempts to answer the research question: What are the issues faced by businesses when they embark on a project to invest in BA and how do they affect firm performance? We employ a qualitative approach to answer these questions. Our study is informed by prior literature and the theoretical perspectives of the Technology-Organisation-Environment (TOE) framework but is not constrained by this theory. This approach has helped us to identify important factors that could extend the applicability of the TOE framework. In the words of Ketokivi and Choi (2014), our research could be classified as theory elaboration. We have not only identified new ways in which traditional TOE factors interact with business performance but also identified new factors that could potentially extend the TOE theory.

\section{Literature survey}

BA helps businesses in terms of demand integration, supply integration, improved customer knowledge, increased processing power, and in many other domains. Wiengarten et al. (2012) suggested that firms might be able to gain significant performance improvements if IT resources (such as BA) are in alignment with additional organizational factors such as organizational strategy, process, culture, and structure; since it is the synergies derived from IT and a variety of complementary organizational factors that will create business value, rather 
than IT alone. This view is seen to be compatible with the TOE framework (Tornatzky and Fleischer, 1990), which is elaborated below.

\subsection{Technology-Organization-Environment (TOE) Literature}

Tornatzky and Fleischer (1990) proposed the TOE framework to study the adoption of technological innovation. They suggested that the decision to adopt a technological innovation is based on factors in the organizational and environmental contexts, and also on the characteristics of the technology itself. The technological context considers existing and emerging technologies relevant to the firm (Hong and Zhu, 2006). Organizational context includes variables responsible for shaping the organisation, including firm size, scope, managerial structure, and internal resources. The environmental context covers: industry, competitors, and dealings with government.

\subsubsection{Technological factors}

Many characteristics of a technology can influence its adoption (Reinmoeller and Ansari, 2015; Rogers 1995; Li 2008; Thong 1999; Tornatzky and Fleischer, 1990; Wang et al 2010; Zhu et al 2006). These include complexity of technologies, compatibility with practices already existing in a firm, perceived benefits, emergence of big-data computing platforms, and technologies that help increase the security of big-data.

\subsubsection{Organizational factors}

The organizational context is described by firm size, complexity of its managerial structure, complementary investments available in the firm, quality of human resources, and amount of slack resources available internally (Tornatzky and Fleischer, 1990; Wang et al., 2010). For example, business strategy, company structure, processes and culture are important organisational factors. 


\subsubsection{Environmental factors}

Environmental factors are those external to an organization that can present constraints and opportunities for technological innovations. This includes business pressure, environmental munificence, complexity, and, dealings with business partners, competitors and the government (Tornatzky and Fleischer, 1990; Zhu et al., 2006; Wang et al., 2010; Li, 2008).

In summary, the TOE framework has been criticized for having unclear major constructs (Wang et al., 2010) and being too generic (Al Nahian Riyadh et al., 2009). Hence, it is argued that the TOE framework needs to be further elaborated to make it applicable to specific contexts. Although TOE has been employed in the context of several other technological innovations (such as e-commerce and radio-frequency identification), it has not yet been employed in the context of BA, making the TOE framework appropriate to explore $\mathrm{BA}$ in retail.

\section{Data collection method and practical perspectives on gathering data}

To achieve the research objectives, our study adopted a qualitative research method using case study. Case study approach can provide detailed and in-depth knowledge of the study object and allow the researcher to explore the research questions in their natural context (Dreyer et al 2011; Junior and Filho, 2016; Pagell and Wu, 2009). Ketokivi and Choi (2014) identify three different methodological approaches to case research: theory generation, theory testing, and theory elaboration. Similarly, Voss et al (2002) also identify four categories of research purpose - exploration, theory-building, theory testing, and theory extension/refinement. According to Ketokivi and Choi (2014), theory elaboration focuses on the contextualized logic of a general theory. They point out that using theory elaboration approach, the researcher may be able to apply an existing general theory, it may be the case that the context is not known well enough to obtain sufficiently detailed premises that could be used in conjunction with the general theory. This is the case for our study. This theory elaboration approach allows us to 
consider more variables than the existing model accounted for, or it also draws our attention to implementation issues, which are worthy of investigation in their own right (Childe 2011). By adopting a qualitative theory elabration approach we would need to ensure a rigorous check for bias in interpretation of the data. This would be done through a team approach to data analysis which would ensure no one-person bias. Early versions of our findings were shared with interview companies whose comments we assimilated.

We followed the eight step process described in Eisenhardt (1989) for the qualitative study:

i. Getting started - to define research questions on the diffusion and impact of Big Data and BA in UK retail and decision on a priori constructs using TOE framework. As mentioned earlier, our main research questions are: "What are the issues faced by businesses when they embark on a project to invest in BA and how do they affect firm performance?" Our Unit of Analysis is a UK retail firm.

ii. Selecting cases using theoretical sampling with potential to extend theory. Interviews were arranged with UK-based retailers and the retail supply chain. Companies were selected from a list of the top 100 retailers in the UK. We aimed for a spread of company size. No distinction was made between those operating off-line, both online and offline, and pure-online retailers. A total of 48 companies were contacted for interviews and 9 of them agreed to participate.

iii. Crafting instruments and protocols with the help of multiple (four) investigators that provide divergent perspectives. Our qualitative approach allowed researchers to collect rich data during the interviews and data gathering process (De Vaus, 2002).

iv. Entering the field - a semi-structured interview questionnaire was developed which incorporated questions addressing key areas of the TOE literature. We agreed however that this would to develop as interviews proceeded.

v. Analysing data using both within-case and cross-case analyses.

vi. Shaping hypotheses - using iterative tabulation of evidence and search evidence for the reasons behind the relationships. Attention was paid to the design, analytical and inferential validity of the study; as they relate to a realist approach.

vii. Enfolding literature for comparison with both conflicting and similar literature. Iterative tabulation, individual and group reflection was used to compare and contrast the extant literature with our findings.

viii. Ending the study when marginal improvement becomes small. 
Interviewees for case 1-8 were provided with a copy of the semi-structured questionnaire a week before interview to enable them to research their answers. Data for entry case 9 was obtained through attendance at a formal presentation by the company and subsequent questions. All interviews were recorded on digital recorder, saved on the project file, backed up and then transcribed. Where possible, two researchers were present at the interviews; all transcripts were checked against the audio files by a team member other than the lead interviewer to ensure transcription reliability. Presentation materials and subsequent questions were recorded and analysed before being added to the project file. Transcriptions varied in size between 2851 words (company 4) and 10104 words (company 8).

NVIVO software was used to organise the data for coding. All transcripts were analysed using three stage coding. Our interview areas provided our initial nodes. Data in each node was then broken down into categories. All passages coded at a particular category were then analysed using interpretation and reflection (Richards, 2009) and memos were created for evolving themes. Cross case analysis within categories allowed us to identify emergent themes which evolved from the interviews through corroboration and contradiction. This process was iterative. The case study approach was finally checked against best practice recommendations of the Linear Model of case research as defined in previous literature (Piekkari, et al, 2010; Halinen and Tornroos, 2005; Yin, 2003).

\section{Case descriptions for within-case data}

Table 1 shows the descriptive statistics for the case companies. The last column shows classification of the case companies in terms of the stage (e.g., leaders, quick adopters, slow adopters or non-adopters) in which they are in implementing BA, and is based on the opinions of the respondents. 


\section{Cross-case patterns and findings}

Cross-case analysis is based on comparing and contrasting the patterns based on the analysis of all available data from all the case firms. There are at least three ways of engaging in crosscase analysis (Barratt et al., 2011): (i) selecting two cases at a time and comparing the differences and similarities, (ii) selecting constructs based on the extant literature and look for the evidences that address these constructs, and (iii) dividing the data by its sources and corroborating the evidence obtained from one form of data source with evidence from another form of data.

Table 1: Description of the case companies

\begin{tabular}{|c|c|c|c|c|c|c|c|}
\hline Coupany & $\begin{array}{l}\text { Size } \\
\text { leusployees }\end{array}$ & $\begin{array}{l}\text { UK Standard Industrial } \\
\text { Code description }\end{array}$ & Description & $\begin{array}{l}\text { Experience } \\
\text { with BA }\end{array}$ & Trading type & $\begin{array}{l}\text { Loyality } \\
\text { scheme }\end{array}$ & $\begin{array}{l}\text { Level of } \mathrm{BA} \\
\text { adoption }\end{array}$ \\
\hline $\mathrm{Cl}^{*}$ & $39.7 \mathrm{~K}$ & $\begin{array}{c}\text { Retail sale of electrical } \\
\text { household appliances in } \\
\text { specialised stores }\end{array}$ & $\begin{array}{l}3000 \text { stores and anciliny services throughour Europe with sales } \\
\text { in excess of fllbilion (2014) }\end{array}$ & $2-5$ years & On offline & No & $\begin{array}{c}\text { Quick } \\
\text { adopter }\end{array}$ \\
\hline $\mathrm{C}_{2}$ & $98.7 \mathrm{~K}$ & $\begin{array}{l}\text { Retail sale in non- } \\
\text { specinlised stores with food. } \\
\text { berverages, or tobacco } \\
\text { dominnting }\end{array}$ & 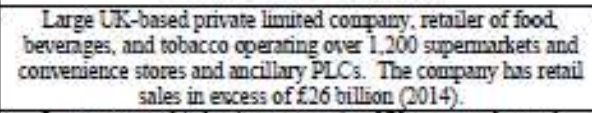 & $6-10$ years & On offline & Yes & Leader \\
\hline $\mathrm{C} 3$ & $74.8 \mathrm{~K}$ & $\begin{array}{l}\text { Engaged in the operation of } \\
\text { department and } \\
\text { superuoriset stores }\end{array}$ & 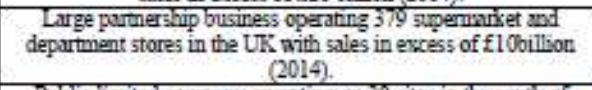 & $2-5$ years & On offline & Yes & $\begin{array}{c}\text { Slow } \\
\text { adopter }\end{array}$ \\
\hline C4 & 496 & Selling used and new cars & $\begin{array}{l}\text { Pablic imited colwany openting on } 30 \text { sites in the south of } \\
\text { England with sales of } f 150 \mathrm{M}(2014) \text {. }\end{array}$ & $>25$ years & Onioffline & No & $\begin{array}{l}\text { Slow } \\
\text { adopter }\end{array}$ \\
\hline $\mathrm{Cs}$ & 96 & $\begin{array}{l}\text { Retail sale via msil order } \\
\text { bouse or the Intemet }\end{array}$ & 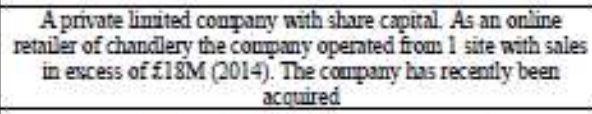 & $6-10$ years & Online only & No & $\begin{array}{l}\text { Quick } \\
\text { adopter }\end{array}$ \\
\hline$\infty$ & $<50$ & $\begin{array}{l}\text { Business and domestic } \\
\text { software developwent }\end{array}$ & $\begin{array}{l}\text { Pivate limited start-up coupany. The company provides } \\
\text { services to consumers and large retail fshion stores unilising } \\
\text { advoured BA around consumer preferences. The coumpany has } \\
\text { been trading for } 4 \text { years. Tumover is exempt froms declanation. }\end{array}$ & $2-5$ years & Online ** & No & $\begin{array}{l}\text { Sell BA } \\
\text { services }\end{array}$ \\
\hline C7 & $<50$ & $\begin{array}{l}\text { Business Intellizence } \\
\text { consuiting coompany serving } \\
\text { Retail and hospinality } \\
\text { comparies }\end{array}$ & $\begin{array}{l}\text { Phivate limitei compuny offering business pefformance and } \\
\text { analytics services to retail customers. It is in the retail trade for } \\
14 \text { yeurs. Tumover is evenpt fom deciaration }\end{array}$ & 13 years & Onvoffline*t & No & $\begin{array}{l}\text { Sell BA } \\
\text { services }\end{array}$ \\
\hline$c 8$ & $1113 \mathrm{~K} * *$ & $\begin{array}{l}\text { Engaged in the wholessle } \\
\text { and retail of computer } \\
\text { relatred goods }\end{array}$ & 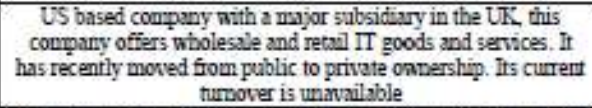 & $11-25$ years & Onioffline & No & $\begin{array}{l}\text { Quick } \\
\text { adopter }\end{array}$ \\
\hline$\infty$ & $7 \mathrm{IK}$ & $\begin{array}{l}\text { Engaged in the retail trade } \\
\text { of health, bevury and } \\
\text { phamusceutical products }\end{array}$ & 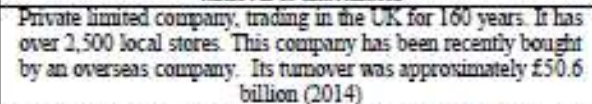 & $2-5$ years & Onioffline & Yes & Leader \\
\hline
\end{tabular}

Key $-{ }^{*} \mathrm{Cl}$ actually encompasses three big retailers in the UK and this interviewee is responsible for the three

** indicates third party provider of BA services

*** user and third party provider of BA services operating worldwide

Since our preliminary constructs are informed by the TOE framework, we have adopted the second way mentioned above. We have presented cross-case analysis here by selecting constructs and looking for evidences. However, as mentioned earlier, we have adopted a flexible approach during our interviews and allowed in-depth descriptions of data to provide additional insights beyond the tenets of the TOE framework. This has helped us to generate 
new insights that can potentially extend the theory further. By doing this, we believe that our research belongs to the mode of theory elaboration (Ketokivi and Choi, 2014) as against the other two modes of theory generation and theory testing. As per Ketokivi and Choi (2014), the mode of theory elaboration focuses on the contextualised logic of a general theory (the TOE framework here). We believe that, though the TOE framework has been successfully applied in numerous contexts on innovations, its applicability in the context of BA is not yet well developed to obtain sufficiently detailed propositions. We thus lay more emphasis on the theoretical framework compared to theory generation but lay lower emphasis compared to theory testing. In contrast, we use empirical data to support theory elaboration to a larger extent compared to theory testing.

First, the themes that support traditional TOE aspects are discussed. Additional themes that extend the theory are discussed in a later section (Section 5.4). In order to conserve space, we present the evidences from our interviewees mainly using tabular format (Tables 2-4).

\subsection{Technology}

There are at least three different kinds of technology assets - human assets, technology assets and relationship assets - in the literature. We have found evidence on the important roles played by all three. Details are presented in Table 2. 
Table 2: Technology issues with Big Data and Business Analytics

\begin{tabular}{|c|c|c|}
\hline & $\begin{array}{ll}\text { Impact criteria } \\
\end{array}$ & Remarks \\
\hline Human assets & 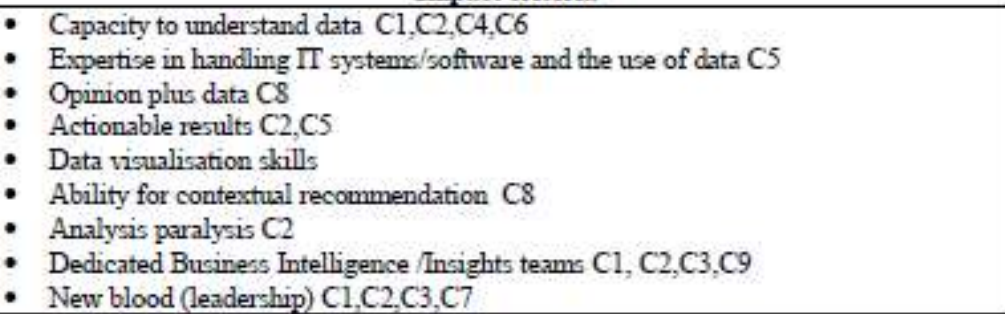 & Direct link to firm performance \\
\hline Technology assets & 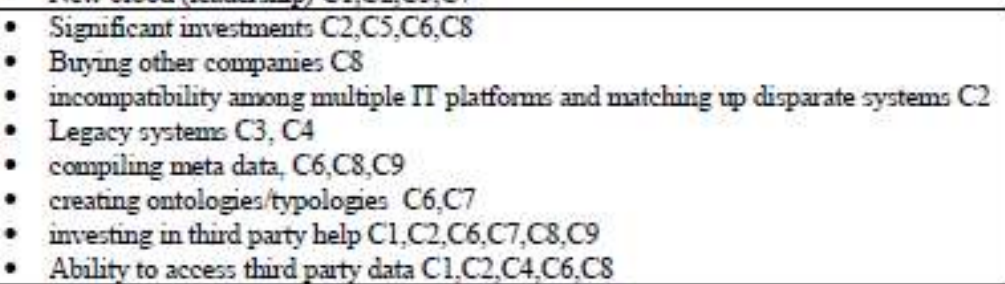 & Link to firm performance \\
\hline Relationship assets & $\begin{array}{l}\text { - External help to adopt and integrate } \mathrm{Cl}, \mathrm{C} 2, \mathrm{C} 7, \mathrm{CS} \\
\text { - Expensive } \mathrm{Cl}, \mathrm{C} 5, \mathrm{CS} \\
\text { - Strategic partners/suypliers of specialist services } \mathrm{Cl}, \mathrm{C} 2, \mathrm{C} 6, \mathrm{C} 7, \mathrm{CS}, \mathrm{Cg} \text {, }\end{array}$ & \\
\hline
\end{tabular}

\subsubsection{IT Human assets}

Our analysis showed that human assets can affect adoption in both a positive and negative way.

The vital importance of IT human assets, particularly the capacity to understand data, has been highlighted as important in assuring success of IT investments in improving business performance (C6). There is a need for the right quality people who have expertise in handling IT systems/software and the use of data $(\mathrm{C} 4, \mathrm{C} 6)$. While almost all our interviewees valued modelling capabilities to engage in business insights, they overwhelmingly stressed the need for proper human interpretation of results of analytics $(\mathrm{C} 2, \mathrm{C} 4, \mathrm{C} 6)$. Interestingly, one interviewee equated the unsophisticated level of people education in his company to its current status as an ineffective user (C4). This provided negative evidence or what Popper (2002) might call a 'black swan'. It also related back to the literature in terms of the importance of human assets and environmental munificence from TOE. One interviewee highlighted the difference between detailed insights and useful insights (C4). A mere number crunching may yield several results but the management needs to exercise judgements in which of these insights are usable and actionable. Other interviewees corroborated the importance of human 
assets in understanding the data, combining data and opinion and having insight $(\mathrm{C} 1, \mathrm{C} 2, \mathrm{C} 4, \mathrm{C} 6, \mathrm{C} 8)$. Two interviewees took this further by relating 'insight' to the human ability to handle what comes next - the 'so what?' (C2,C5)

Leaders and quick adopters usually had dedicated human resources for BA in the form of Business Development posts or Business Insights departments. An interesting point also emerged whereby many BA campaigns had been instigated and supported by 'new blood' in the company in the form of new CEOs or new lower level management au fait with the use of data for prediction.

\subsubsection{Technology Assets}

Six of our interviewees highlighted that technology assets play a crucial role in successful implementation of $\mathrm{BA}$ in their organisations $(\mathrm{C} 2, \mathrm{C} 4, \mathrm{C} 5, \mathrm{C} 6, \mathrm{C} 7, \mathrm{C} 8)$. These assets could be in the form of physical IT hardware, different technological platforms, development and maintenance of databases, data architecture and definitions. It was highlighted that benefits of BA are more visible when they are pursued for longer. Several interviewees highlighted that incompatibility among multiple IT platforms was a potential barrier to BA adoption. Some of these issues were related to the presence of legacy systems or not owning their own data. The incompatibility affected the level of IT integration and hence reduced the benefit the firms would otherwise derive from technology assets $(\mathrm{C} 3, \mathrm{C} 4, \mathrm{C} 7)$.

The importance of organisational culture was highlighted. Even if the right technology is in place, numerical results of BA cannot guarantee improved business performance. There is also the recognition that culture cannot be changed overnight and that it is a slow process, ultimately requiring buy-in from key functions $(\mathrm{C} 1, \mathrm{C} 2, \mathrm{C} 3, \mathrm{C} 4, \mathrm{C} 7)$.

An appropriate organisation structure is important to provide visibility that will drive performance. Schoenherr and Speier-Pero (2015) argue that linked to the adoption of business analytics is the organizational structure that is implemented to promote and support enterprise 
analytics' activities and call for specific evidence of linking this factor to BA adoption success. Amongst the leaders and fast adopters 'customer insights teams' were common $(\mathrm{C} 1, \mathrm{C} 2, \mathrm{C} 3, \mathrm{C} 5, \mathrm{C} 9)$. One fast adopter had its own Centre of Excellence dealing with business intelligence and BA. Following successful use of BA for its own business it now sold solutions externally (C8).

Low volume, infrequent sellers implied there were advantages to centralised systems and clear lines of governance. High volume, frequent sellers appear to have moved past this operational problem of using BA for supply chain efficiencies to the problems of using BA for predicting customer buy. One interviewee likened this as a move from 'evolutionary analytics to revolutionary analytics' with the customer at its centre (C8).

\subsubsection{Relationship assets}

The literature suggests that relationship assets are important in harnessing the benefits of IT investments.

When discussing 'insight' we have already mentioned that 4 of our interviewees, mostly leaders or fast adopters, relied on external help to both adopt and integrate IT; BA algorithms and data security requirements $(\mathrm{C} 1, \mathrm{C} 2, \mathrm{C} 3, \mathrm{C} 9)$, while 3 provided these services $(\mathrm{C} 6, \mathrm{C} 7, \mathrm{C} 8)$. Another aspired to retain an expert consultant but found the expenditure prohibitive (C5). Another adopter $(\mathrm{C} 1)$ however remained unconvinced of the value of consultants. Relationship assets could be in the form of partnerships with other divisions and external organisations, supplier relationships etc. Our interviews have provided evidence on the importance of relationship assets in the adoption and integration between IT and processes, with several parties stressing that finding the right partner is integral to the success of BA in their firms or at least to the ongoing development of BA $(\mathrm{C} 2, \mathrm{C} 8)$. Interestingly, one of our interviewees pointed out that this tendency to third party usage replicated its main competitor who did the same (C2). 


\subsection{Organisation}

Evidences from our interviewees on organisational support are presented in Table 3.

\begin{tabular}{|c|c|c|}
\hline & Impact criteria & Remarks \\
\hline Application Domains & $\begin{array}{l}\text { - More domains (Table 4) for leaders (C2,C9) } \\
\text { - More difficulties on ommi-channel trading (slow online adopters) } \\
\text { - Top matations with legacy systems (slow adopters) (C3,C7) } \\
\text { Topent support is crucial }\end{array}$ & $\begin{array}{l}\text { Leaders use BA in } 8 \text { domains and above; Quick } \\
\text { adopters in 5-7 domains; Slow adopters in }>5 \\
\text { domains }\end{array}$ \\
\hline Complementary investments & $\begin{array}{l}\text { - Third party data - /social media/credit cards/land registry/specialist } \\
\text { data providers }(\mathrm{Cl}, \mathrm{C} 2, \mathrm{C} 4, \mathrm{C} 6, \mathrm{C} 7, \mathrm{CS})\end{array}$ & $\begin{array}{l}\text { Larger retailers have more comprehensive } \\
\text { internal data due to multiple opportumities to } \\
\text { collect data e.g. sale of goods and services, } \\
\text { loyalty schemes }(C 2, C 7, C 9)\end{array}$ \\
\hline
\end{tabular}

\subsubsection{Application domains}

Common sense tells us that there is a timeline between IT integration and business performance and an effect between the extent to which BA is adopted and business performance. In our interviews we captured the areas of the business in which BA was used (application domains - please see Table 4) by directly asking the respondents. The level of adoption is used to describe to speed of adoption. Interviewees tended to rate themselves with reference to their direct competitors however one interviewee $(\mathrm{C} 8)$ did this in relation to its own upstream supply chain. The order of adoption is leader, quick adopter, slow adopter, nonadopter. The information about the level of adoption has already been provided in Table 1, and the information is reproduced in Table 4 for convenience.

Table 4: Domains and adoption status of interviewees

\begin{tabular}{|c|c|c|c|c|c|c|c|c|c|c|c|c|}
\hline 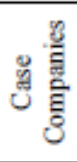 & 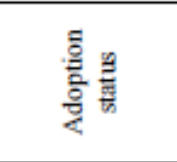 & 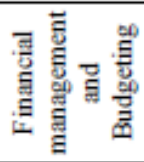 & 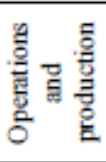 & 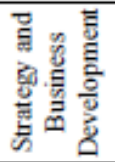 & 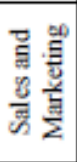 & 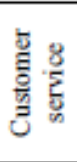 & $\begin{array}{l}\frac{\partial}{2} \\
\frac{2}{2} \\
\frac{\partial}{2} \\
\frac{\partial}{2}\end{array}$ & 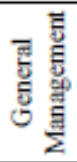 & 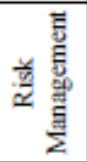 & 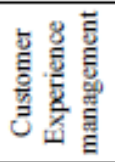 & 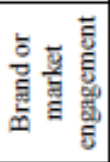 & 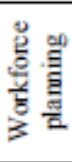 \\
\hline $\mathrm{C} 1$ & Quick adopter & Yes & Yes & Yes & Yes & Yes & & & & & & \\
\hline $\mathrm{C} 2$ & Leader & Yes & Yes & Yes & Yes & Yes & & & & Yes & Yes & Yes \\
\hline $\mathrm{C} 3$ & Slow adopter & & Yes & Yes & Yes & & & & & & & Yes \\
\hline $\mathrm{C} 4$ & Slow adopter & & & & Yes & & & Yes & & & & \\
\hline $\mathrm{C5}$ & Quick adopter & Yes & Yes & Yes & Yes & Yes & & & & Yes & & \\
\hline $\mathrm{C} 6$ & \multirow{2}{*}{\multicolumn{12}{|c|}{ These companies provide BA consultancy services }} \\
\hline C7 & & & & & & & & & & & & \\
\hline $\mathrm{C} 8$ & Quick adopter & Yes & Yes & & Yes & Yes & Yes & & & Yes & Yes & \\
\hline $\mathrm{Cg}$ & Leader & Yes & Yes & Yes & Yes & Yes & & Yes & & Yes & Yes & Yes \\
\hline
\end{tabular}

Key: shaded rows indicate companies that do not sell products to consumers, but are third party suppliers of BA products/services to other businesses

Domains as defined by IBM (2011) 
Here we use the number of application domains where BA has been adopted as a proxy for Organisational support. While some of our interviewees mentioned only two or three areas (C3,C4), many others mentioned a wide variety of domains (e.g., C2, C5,C9)

In general, slow adopters $(\mathrm{C} 3, \mathrm{C} 4)$ mentioned mainly operations and marketing as the main application domain, while leaders had interest in using BA in more domains. Many respondents highlighted specific domains in which BA has helped improve firm performance. Quick adopters/leaders $(\mathrm{C} 1, \mathrm{C} 2, \mathrm{C} 5, \mathrm{C} 8, \mathrm{C} 9)$ explicitly mentioned that effective use of BA in their firms helped them to gain a better understanding of customers, which in turn benefitted them in improving customer orientation culture in their organisations. Table 4 shows the domains covered by BA and the adoption status of each of our interviewees. It appears that lead users appear to be active in more domains. Of those interviewed, those new to online trading $(\mathrm{C} 3, \mathrm{C} 4)$ experienced more difficulties due to the IT legacy and cultural issues of embracing omni-channel trading.

"lead times are less than 48 hours now...from order to a shop...they can be 8 hours for online...the cultural, behavioural part has not caught up with the operational capability to be honest...you have still got some buyers who go I don't trust 48 hours so I'd better order a bit more..." C3

Issues that surfaced in the level of adoption was the braking effect of legacy systems; the need to benchmark externally; the 'frequency of customer' buy; whether it was an 'emotional buy' and the level of single item spend which together appears to moderate what can be achieved by BA in terms of business performance. Another issue was that different areas of the companies were ahead and some behind regarding integration.

\subsubsection{Complementary investments}

Complementary investments have already been discussed during discussion of technology assets. However, Interviewees in cases 1,2,3,9 also highlighted that it was important to complement their in-house data with third party databases (e.g., credit card data, Google analytics, utilities, loyalty cards, financial services, etc.) to help understand their customers 
better. This echoes with the growing popularity of third party social media sites such as

Twitter in business analytics in the context of supply chain research (Chae, 2015).

\subsection{Business Environment}

Table 5 provides a list of impact criteria in business environmental context from the interviewees. The details are elaborated below.

Table 5: Business Environment issues with Big Data and Business Analytics

\begin{tabular}{|l|l|l|}
\hline & \multicolumn{1}{|c|}{ Impact criteria } & \multicolumn{1}{c|}{ Remarks } \\
\hline Market Environment & $\begin{array}{l}\text { Type and form of governance impacts the degree of organisational } \\
\text { support for a change to a } \mathrm{BA} \text {-based culture } \mathrm{C} 2, \mathrm{C} 3, \mathrm{C} 7\end{array}$ & $\begin{array}{l}\text { Omnni-channel markets affect firm performance positively } \\
\mathrm{C} 2, \mathrm{C} 3 . \mathrm{C} 6\end{array}$ \\
\hline Business Pressures & $\begin{array}{l}\text { Cost pressure } \mathrm{C} 1, \mathrm{C} 2, \mathrm{C} 3, \mathrm{C} 4, \mathrm{C} 5, \mathrm{C} 6 . \mathrm{C} 7 \mathrm{C} 7 \\
\text { Regulatory pressure } \\
\mathrm{C} 1, \mathrm{C} 2, \mathrm{C} 3, \mathrm{C} 6 . \mathrm{C} 7\end{array}$ & $\begin{array}{l}\text { Frequency of buy could be a mediator between business } \\
\text { pressures and } \mathrm{BA} \text { adoption. } \\
\mathrm{Cl}, \mathrm{C} 4\end{array}$ \\
\hline
\end{tabular}

\subsubsection{Market environment}

In this study, our ability to generate specific conclusions was limited by the nature of our sample. We focussed only on the retail sector, and hence our sample firms operated in a relatively homogenous environment be it highly competitive and with equal physical if not financial access to resources. At the time of interviewing $8 / 9$ of our interviews focussed on UK-based companies. Hence, the main variations in business environment were associated with governance and whether our retailers offered goods and/or services; and whether they operated offline, online, or both.

Our interviewees were different types of businesses; subject to different forms of governance varying from PLCs to partnerships to private companies. In one instance, an interviewee referred to how by proffering its successful use of BA it could influence the City's opinion and therefore by inference its share price. Another company mentioned how its philosophy with regard to implementing BA was not city-orientated. The same company commented that the company strategy, whether it be growth or efficiency effectively dictated the speed of implementation and not the City's viewpoint of it. It would seem therefore that the degree of 
organisational support for a change to a BA-based culture could be contingent on the type and form of governance of the company.

Businesses that have multiple channels to reach customers may be able to get additional insights on customer behaviour. In addition to this, the availability of a Loyalty Scheme is a good indicator that additional data is being collected. 3 of our interviewees operated an inhouse Loyalty scheme (Table 1). A firm operating across multiple channels claimed that its multiple channel customers spent significantly more. This would suggest that the level of adoption is related not only to the type of business but also to the business performance in terms of turnover per client.

In conclusion the study shows a direct relationship between market environment as described by whether the company is omni-channel and operating a loyalty scheme, the current company strategy (save or make money), and its governance structure. Further, there is some evidence that there may be a direct relationship between omni-channel operation and business performance.

\subsubsection{Business pressures}

All our respondent firms faced business pressures in the form of cost pressures, needing to understand the needs of large numbers of customers and regulatory pressures. Cost pressures are one of the prime reasons for using BA. Cost pressures have forced our respondent firms to improve their understanding of customers, target profitable customers, and understand the frequency of their transactions so that they may efficiently target advertising campaigns. The overriding need to understand customers, especially on a global scale and if you are a big company was also evident.

Another issue under environmental context was the issue of 'buy type'. It would seem that the frequency of buy affects level of adoption and specifically the integration between IT and strategy and processes. 
Regulatory pressures have affected our respondent firms. All respondents highlighted how they would ensure that their BA-based online campaigns would comply with recent legislation on cookie-related legislations and credit-card related legislations, and the more traditional UK Data Protection Act (2008).

As a summary of this section so far, our results have shown that all the three components of the TOE theory - technology, organisation and environment - have significant influence in helping the adoption of BA. This finding is sketched in Figure 1 and is consistent with prior TOE literature (e.g., Awa et al., 2015; Baker, 2012).

Therefore, based on our analysis, we have

Proposition 1: TOE elements in the context of BA have significant influence on BA adoption.

Technology context

IT assets

Thuman assets $\left\{e . \mathrm{E}_{\text {; }}\right.$ techrical stalk bushess understandine problem solvire orientation?

Fedinologyasesta if is technological platfoms, customer databases, architectures, sottware toolsistandards ontologies, meca daca Detinicionsi

Organisation support rop level suppore/ new blood Complementary investmenss in organisational stratedy, structure, process and cuture ies, access to Euternal data)

Number of application domains within a business for veint business anatytics (erf. CRM, online advertising, etc)

Environment context Butiness type - fowemance Boy type/ buy frequency Busines pressure

Cost reduction regulation, supply choin tficency avalable benchmands

Market environmen:

Environmental complevity and Oma channel behawaar
Adoption of BA 


\subsection{Additional factors that support extension and elaboration of TOE theory}

While the discussion with our interviewees have generally supported areas already in the literature, we did find evidence of the involvement of additional factors in ensuring how firms could maximise benefit derived from BA.

\subsubsection{Business Performance}

While most studies in the TOE literature argue that the TOE elements facilitate adoption of technology, we have found evidence in this study that there is link between the adoption of BA and performance of the firms adopting it. A unanimous opinion from our respondents is that a low level of BA integration may have negative impacts on business performance. An interviewee who called his firm as a slow adopter highlighted that they could not derive much benefit of BA because they kept wasting time and effort \{process organisation related\} as they did not have properly integrated systems. This was further corroborated by the fact that interviewees $(\mathrm{C} 1, \mathrm{C} 2, \mathrm{C} 3)$, saw the importance of, and strived towards, a common customer database.

"Setting up a single customer database, there was a fair bit of investment in that... we've got 30 million customers in the UK on that some infrastructure costs in getting that right," C1

"... as we are now building up quite a lot of data...we understand a lot... we have deep consistent meta data every single product, every single customer, every single brand" C6

It was easier for many interviewees to identify BA-caused benefits on performance in terms of process level (e.g., marketing effectiveness, lead time reduction, etc.) rather than at the firm 
level ( Return on Investment); however one interviewee (C6) was adamant that it saved its clients money.

“...we can help them deliver huge value on their own KPIs... " C6

“...Understanding big marketing and promotions so we can see the effectiveness of our media campaigns has improved over time...our ability to forecast particularly big events has got better as well... that's improved sales and reduced costs...we have got a better understanding of what products customers want so that's improved the efficiency of our stores in just the range and selection..." C2

There is recognition that investments in BA need to be prioritised.

“...80\% of DM campaigns comes form $20 \%$ of contacts ...very profitability campaign if you can find the $20 \%$... and forget about the rest of it ...it's forced us to prioritise the areas that we can get biggest benefit out of faster" C5

This prioritisation was also interpreted as the famous Pareto or 80:20 rule. One interviewee mentioned about the 80:20 rule in getting benefits from BA, saying easier benefits can be experienced with low to moderate investments in BA while additional incremental benefits may require more substantial investment.

"Go back to the board... actually the 80/20 rule applied to the dollar....it was an excellent presentation...80\% of potential configurations were never purchased, not even occasionally, never...so one of the great benefits of combined BI and brain power was that we could actually look at what we were doing and make sense of it..." $\mathrm{C} 8$

This use of the 80:20 rule highlights that even a slow adopter who makes moderate investment may be able to get reasonable benefits from BA.

In conclusion, few of our interviewees could quantify the effect of BA on Business performance but were able to quantify local impacts at a process or functional level, e.g., Marketing and supply chain efficiencies.

“... its actually...always very difficult to say where the direct benefit is... there isn't a direct financial benefit...it usually enables something else” C5

“...we've also seen a quite big improvement in customer awareness and customer engagement and also price perception and all of those are as a direct result of the some of the analysis we've done" C2

Based on these observations, we feel that there is evidence to link TOE elements to business performance via adoption. In other words, once a firm adopts BA, there is evidence of impact on business performance. This result is supported by the findings of Troilo et al. (2016), though their study did not use TOE theory. 


\subsubsection{BA adoption could be potentially linked to environmental sustainability}

Another interesting observation from our study is that some of our interviewees have found interesting links between a firm's investments in BA and its engagement in terms of improving their environmental sustainability initiatives. Sustainability is most commonly defined as the development that meets the needs of the present without compromising the ability of future generations to meet their own needs (Brundtland, 1987; Mebratu, 1998). Environmental sustainability issues have been at the forefront of business strategies for nearly two decades if not longer. While investments by firms in environmental sustainability activities can be considered as a burden on their profits, there also a general belief that firms with proactive initiatives in improving environmental sustainability are benefiting in the form of improved image and reduced waste (Orlitzky et al., 2003; Yu and Ramanathan, 2015). However, there is a paucity of research that links the field of information systems and environmental sustainability (Melville, 2010).

Interestingly, (C1,C2,C5,C6,C7) recognised the link between BA and sustainability. They highlighted that the benefits they obtained from BA, in response to cost pressures, also helped them indirectly in improving their environmental sustainability mainly by improved efficiencies or waste reduction.

" sustainability, yes, it's always there...most of it tends to relate to carbon foot print... it doesn't tend to be our primary focus... but its one of those where you get the delivery efficiency you're looking for...it's not our first aim...we need to make sure we are doing it as well as cost efficiency...cost efficiency is our primary reason for being in life..." C2

One of our interviewees was able to identify a number of ways its clients improved their environmental performance through the use of its BA (C6).

"...if we know through our customer base that $80 \%$ plus sizes are never going to wear a certain sleeve then don't make that dress with that sleeve...one environmental impact..."C6 
Another recognised that printing fewer magazines meant less landfill (C5).

“...although our turnover has grown last three years 30, 35, 20\%, we're not printing any more catalogues than we did two years ago...we've met the need" C5

The other businesses recognised the effect of BA on environmental performance as incidental; a repercussion of achieving supply chain efficiencies. Even where companies were required to conform to legislation e.g., WEEE, BA was a factor in achieving the required levels of distribution and warehousing efficiencies.

“...generally having tighter control of the supply chain...seen stock levels come down significantly and also the allocation of stock has significantly improved as well...supply chain costs have come down...we've been able to consolidate the warehousing...WEEE puts huge pressure on costs; has meant that where there's an opportunity to improve distribution efficiency, ...good for environmental as well as bottom line..." $\mathrm{C} 1$

In summary, five of nine interviewees could recognise the positive impact of BA on their environmental performance either directly or indirectly.

Thus, based on this analysis, we posit:

\section{Proposition 2a: BA Adoption will help influence environmental performance positively.}

\subsubsection{Moderating role of level of adoption}

For this sub-section and beyond, we distinguish between adoption and level of adoption: while several firms can adopt BA, they differ in terms of the level of adoption. For example, both the leader and slow adopter have adopted BA but the former has shown more willingness than the latter in adopting BA. The difference between adoption and levels of adoption has been highlighted in the innovation literature. For example, of the five stages (namely knowledge, persuasion, decision, implementation and confirmation) of adoption of an innovation (Peters, 
2012), adopters decide about adopting an innovation at the decision stage but they differ in the degree in which they decide to adopt at the implementation stage.

Much of the discussion in Sections $5.1-5.3$ above have highlighted the important role played by the level of adoption of BA. For example, leaders and quick adopters had specialist human resources and dedicated centres of excellence for BA.

They proactively obtained external (relationship asset) help to understand customers. Leaders and quick adopters use BA in more application domains (Table4). These leaders and quick adopters $(\mathrm{C} 2, \mathrm{C} 9, \mathrm{C} 1, \mathrm{C} 5, \mathrm{C} 8)$ are able to identify benefits more easily than slow adopters $(\mathrm{C} 3, \mathrm{C} 4)$. Thus, we have evidence to argue on the moderating role of level of adoption - the stronger BA adoption by a firm, the better it perceives positive impacts on its performance. Thus we propose:

\section{Proposition 3: Level of adoption of $B A$ moderates the link between BA adoption and} performance.

We feel that this finding is important and provide important contribution to the TOE theory because several of TOE studies have considered level of adoption as the dependent variable (e.g., Hsu et al., 2014; Safavi et al., 2014; Kurnia, 2015) but not as a moderator. The closest study appears to be that of Yen-Lin (2013), who has shown that technology readiness moderates the relationship between information system quality and organizational performance.

\subsubsection{Moderating role of level of integration of IT with business strategies}

Similarly, we have found evidence for moderating role of another important factor, namely the level of integration between IT and strategies in the organisation. The integration issue has emerged as an important factor for BA impact in our studies. We have specifically summarized the key issues associated with the integration in Table 6. For example, integration between 
human assets, technology infrastructure and complementary investments have been highlighted. Presence of dedicated customer insight teams ensure adequate level of integration of IT with other business strategies and help in achieving better firm performance. There is evidence for increased integration of IT with organisational strategy when BA was used in more application domains in a firm, which, in turn, results in better firm performance. Thus we feel that the level of integration of IT with various business strategies could provide a moderating influence on the link between TOE elements and performance. A higher level of integration will result in better firm performance. In other words, the stronger IT integration in a firm, the better it perceives positive impacts on its performance.

Table 6: Integration issues with Big Data and Business Analytics

\begin{tabular}{|c|c|}
\hline & Integration issues \\
\hline \multicolumn{2}{|l|}{ TECHNOLOGY } \\
\hline Human assets & $\begin{array}{l}\text { - Link to organisational culture, mission, leadership (Cl,C2,C3, C7) } \\
\text { - Understanding of behavioural issues of customers (e.g., emotional buying for fashion products), importance of 'data plus } \\
\text { insight'. (C1,C4,C5,C8) } \\
\text { - Human assets should complement investment in technology infrastructure (ability to understand data) }(\mathrm{Cl}, \mathrm{C} 4, \mathrm{C} 5, \mathrm{CB}) \\
\text { - Dedicated customer insight teams/business intelligence excellence centre (C2,C9) } \\
\text { - Ability to sell BA solutions externally (C9) }\end{array}$ \\
\hline Technology assets & - Potential conflicts with multiple sales channels $(\mathrm{Cl}, \mathrm{C} 2, \mathrm{C} 3, \mathrm{C} 9)$ \\
\hline Relationship assets & $\begin{array}{l}\text { - There is a relationship between relationship assets and the level of adoption and integration } \\
\text { - There are mixed views on the value of relationship assets. Three quick adopters }(\mathrm{Cl}, \mathrm{C} 5) \text { and two slow adopters }(\mathrm{C} 3, \mathrm{C} 4) \\
\text { remained unconvinced of the value. Both leaders and one quick adopter saw value }(\mathrm{C} 2, \mathrm{C}, \mathrm{C} 9) \text {. The remaining two were } \\
\text { providers of services. }\end{array}$ \\
\hline \multicolumn{2}{|r|}{ 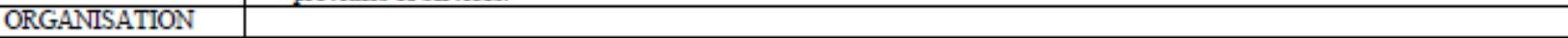 } \\
\hline Application Domains & - Increased integration of $\Pi \mathrm{T}$ with organisational strategy when BA was used in more application domains in a firm. See Table 4 \\
\hline ENVIRONMENT & \\
\hline Business Pressures & - Understanding customers better results in reduced retum thereby reducing cost (C6) \\
\hline
\end{tabular}

Literature has suggested that IT integration can impact on IT business value. For example, recently, Ding et al (2011) state that "integration is the key" emphasising the importance of intra- and inter- organisational integration of IT systems. Ji-fan Ren, et al (2016) have identified that systems integration as a key indicator of system quality contributes to better business value and firm performance in a big data environment. However, studies on the impact of IT integration in TOE theory are quite limited. Palacios-Marqués et al. (2015) have hypothesised IT integration as an independent variable influencing knowledge exchange via the web but did not find support empirically. Chowanetz et al. (2012), in their survey of information systems research literature, have highlighted the lack of studies that specifically 
looks at the role of integration. They have further highlighted that the amount of publications that specifically focussed on moderating influence of integration was very limited. Our study thus provides interesting evidence on the moderating role of integration in the context of BA. Based on our analysis, we posit:

\section{Proposition 4: Level of integration between IT and business strategies moderates the link} between BA adoption and performance.

\subsubsection{The moderating influence of trust}

An element frequently discussed by our respondents was the trust in new BA systems in predicting the behaviour of supply chain partners. Trust is a widely researched term in IT innovation literature mainly in the context of inter-organisational relationships (Goo et al., 2009; McKnight et al., 1998). However, this term has not been conceptualised in the context of TOE theory by many studies. To our knowledge, there are no studies that considered that trust as a part of any of the TOE elements. However, there are a few studies that have conceptualised how trust could affect the link between TOE elements and other related concepts. For example, Li et al. (2015) have conceptualised trust as a mediator between TOE elements and cloud computing adoption intention. In contrast, we have found that our interviewees have provided evidence for a moderating role of trust in the context of BA.

A higher level of trust in BA systems generally resulted in lower levels of stock as firms are more confident of receiving stock from suppliers on time. On the contrary, a lower level of trust in BA systems would mean that firms are not confident about supplies from suppliers and prefer to increase their levels of inventory which increases cost. This observation is clear from the following quote from one of our respondents.

“...the biggest culture change is a 'trust' ...if I give you an example oferm...probably less than 15 years ago there was one distribution centre for \{name withheld\} ... and lead time for stock into shops was about 3 weeks...erm... and so buyers (employees) behaved in a certain way... because they had to buy at a certain time...they knew it was always going to be late... As you get more 
efficient and you have a proper supply chain with more Distribution Centres ...lead times can be 8 hours for online...the cultural, behavioural part has not caught up with the operational capability to be honest...you have still got some buyers who go I don't trust 48 hours so I'd better order a bit more... " C3

Human nature informs us that things go wrong and that data by itself is fallible and that intuition has value. This perhaps explains the reoccurring theme within our research of the need for 'data plus insight or intuition', as one respondents points out that it is "important to maintain the strength of intuition whilst people are looking at [data] ..." C1

We feel that the role of trust has both theoretical and managerial implications.

In terms of theoretical implications, this observation calls for the need to consider trust, a hitherto under explored concept in TOE theory, as a regular new concept. Though trust is a well-explored concept in the literature, there are only a few studies that have linked trust with the TOE theory. Only a few studies have highlighted how trust could provide a mediating role in the context of TOE models (e.g., Li et al. 2015). Our study points to the need to explore the role of trust on the relationships among TOE elements and performance more widely in future studies. Therefore, we posit

\section{Proposition 5: Trust in BA systems moderates the link between BA adoption and} performance.

Inclusion of the impact of trust on the framework in Figure 1 has significant managerial implications. Since inventory impacts performance, we feel that there exists a moderating relationship of trust between the level of adoption and performance shown in Figure 1. High levels of trust would reduce inventory (better performance) while low levels of trust would increase inventory. 


\section{Discussion and conclusions}

Our study has made several important contributions to the literature. First, we have verified the tenets of the TOE literature in the context of the adoption of business analytics in UK retail sector. However, our results have also provided further possibilities of extending the TOE theory by suggesting further links and moderation possibilities. We explain the important contributions of our study with further links to the literature in Table 7 below.

Table 7: Main contributions of our study and links to the literature

\begin{tabular}{|c|c|c|c|}
\hline Contribution & Supporting literature & Contrasting literature & Remarks \\
\hline $\begin{array}{l}\text { Verifying the application of TOE } \\
\text { theory for the adoption of BA in } \\
\text { UK retail (Proposition 1) }\end{array}$ & $\begin{array}{l}\text { Awa et al (2015); Baker } \\
(2012)\end{array}$ & - & \\
\hline $\begin{array}{l}\text { Link between adoption and } \\
\text { business performance } \\
\text { (Proposition 2) }\end{array}$ & Troilo et al. (2016) & - & $\begin{array}{l}\text { The supporting literature was not in the } \\
\text { context of TOE theory. }\end{array}$ \\
\hline $\begin{array}{l}\text { Link between adoption and } \\
\text { environmental performance } \\
\text { (Proposition 2a) }\end{array}$ & - & - & $\begin{array}{l}\text { This is our new contribution to the } \\
\text { literature. This link has not been } \\
\text { discussed in previous literature though } \\
\text { the need to conduct further research on } \\
\text { this link was anecdotally mentioned in } \\
\text { Melville (2010). }\end{array}$ \\
\hline $\begin{array}{l}\text { Moderating influence of the level } \\
\text { of adoption (Proposition 3) }\end{array}$ & Yen-Lin (2013) & $\begin{array}{l}\text { Hsu et al. (2014), Safavi et al. } \\
\text { (2014), and Kumia (2015) used } \\
\text { level of adoption as the outcome } \\
\text { variable but not as a moderator }\end{array}$ & $\begin{array}{l}\text { Yen-Lin (2013) did not consider the } \\
\text { context of TOE theory. }\end{array}$ \\
\hline $\begin{array}{l}\text { Moderating role of level of } \\
\text { integration of } \Pi \text { (Proposition 4) }\end{array}$ & $\begin{array}{l}\text { Ding et al. (2011) has } \\
\text { highlighted the importance } \\
\text { of IT integration using } \\
\text { value chain theory but not } \\
\text { in TOE context. Ji-fan Ren } \\
\text { et al }(2016) \text { have also } \\
\text { focussed on } \Pi \text { integration. }\end{array}$ & $\begin{array}{l}\text { However, both these studies (Ding } \\
\text { et al., 2014; } \sqrt{1}_{1} \text {-fan Ren et al., 2016) } \\
\text { did not consider the moderating } \\
\text { impact. }\end{array}$ & $\begin{array}{l}\text { Chowanetz et al. (2012) have } \\
\text { highlighted that literature needs more } \\
\text { empirical studies linking level of IT } \\
\text { integration, especially those that focus } \\
\text { on moderation. Our study fills this void } \\
\text { by contributing to this specific } \\
\text { literature. }\end{array}$ \\
\hline $\begin{array}{l}\text { Moderating influence of trust } \\
\text { (Proposition 5) }\end{array}$ & - & $\begin{array}{l}\text { Li et al. (2015) have conceptualised } \\
\text { trust as a mediator between TOE } \\
\text { elements and cloud computing } \\
\text { adoption intention. }\end{array}$ & $\begin{array}{l}\text { Ours is the first empirical study where a } \\
\text { moderating role of trust has been } \\
\text { conceptualised in TOE context for BA. }\end{array}$ \\
\hline
\end{tabular}

\subsection{Theoretical implications}

Our study supports existing TOE literature. However, the findings from our interviews have shed new insights that elaborate the theory further and can extend its scope as to how they relate to retail.

In line with the TOE literature, we find that important technology assets are technological platforms, customer databases, architectures, standards, ontologies, meta data, and definitions. However, in addition to the traditional TOE factors, our study has further identified new factors 
that could potentially extend the TOE theory. They include a link to business performance (along with environmental performance), and, the moderating roles of level of adoption, integration and trust.

Figure 2 illustrates our revised conceptual model of BA diffusion in the retail sector. This combines existing theory with additional factors found in our study.

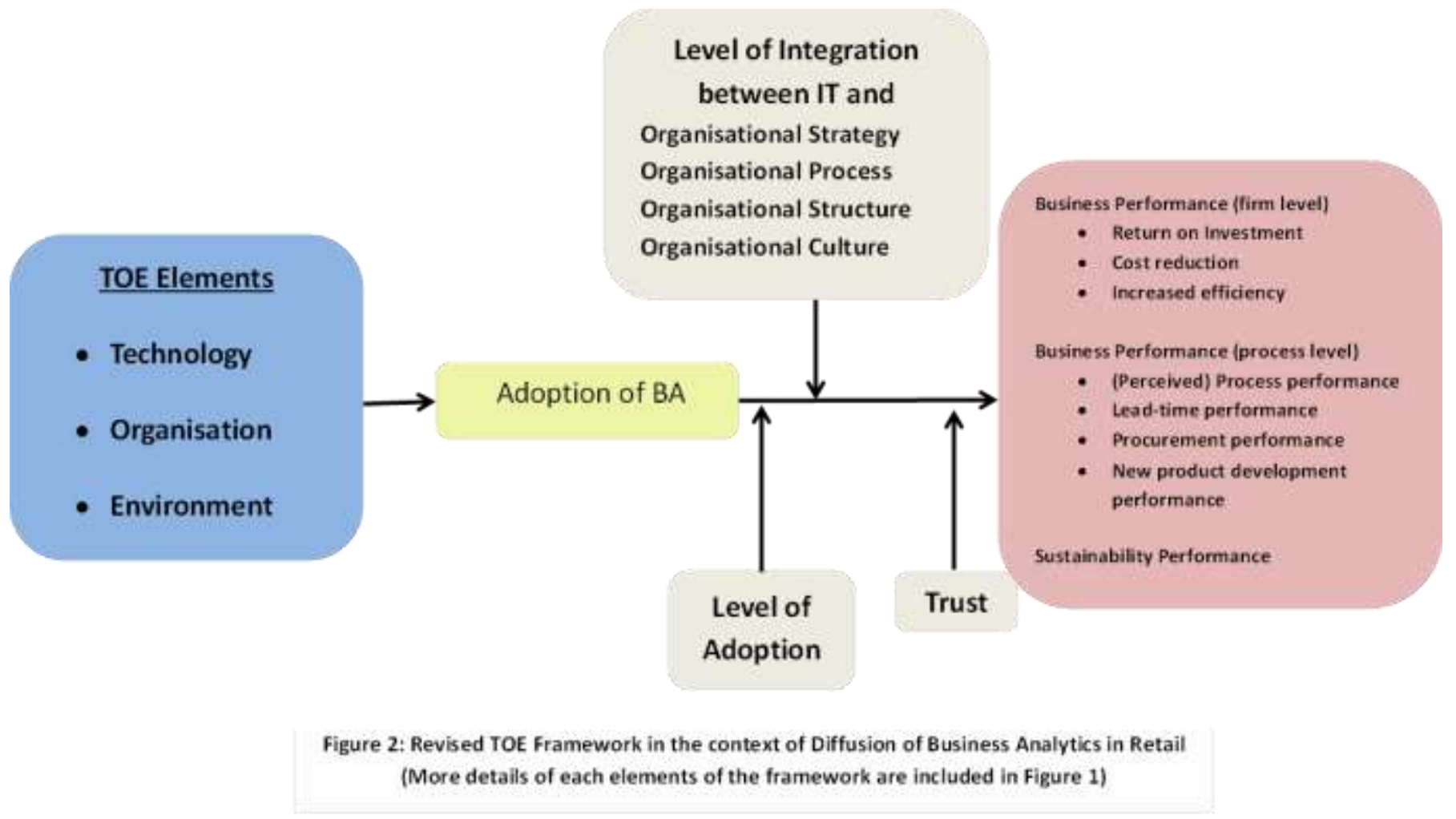

\subsection{Managerial implications}

There is sufficient evidence in our research that BA helps improve firm performance both in terms of saving money (operations) and making money (marketing). There is in general a similar view in the literature that IT investments have potential to enhance a firm's performance in value chain activities investments (Armstrong and Sambamurthy 1999; Porter, 1985; Sethi and King 1994).

Our study goes beyond the existing literature in that the results of investments in BA can be quantified more easily at the process level than at the firm level. This result may provide another interesting interpretation of the so called "productivity paradox" (Brynjolfsson, 1993); 
the results of IT investments such as those in BA are more explicit at process level, which may or may not ultimately translate to firm performance. Process level performance may act as a mediator between IT investments and firm performance. The link between IT investments and process level performance may be stronger but the link between process level performance and firm level performance may or may not be strong enough. Legacy systems impede the implementation of BA. Our study has supported the findings of Reinmoeller and Ansari (2015) in that the role of stigmatised practices and legacy systems have reduced the benefits that could have been derived with business analytics otherwise.

Slow adopters can gain by implementing simple analytics tools. Pareto rule is valid with BA in that $80 \%$ of benefits can be obtained with $20 \%$ of investments. However, more sustained benefits can be obtained by integrating BA with other processes (such as logistics and supply chains) as highlighted by Lee and Whang (2001). Human factors such as strong leadership and commitment, appropriately skilled IT human assets, relationships with external companies and complicit organisational culture play an important part in successful implementation. The importance of having skilled data analysts is also highlighted by Schoenherr and Speier-Pero (2015)

'New blood' in the company was a facilitator of adoption, as echoed by the findings of Chatterjee et al. (2002), Grover and Goslar (1993) and Teo and Ranganathan (2004). This has important implications for innovation in general and the impact of the mobility of specific workforces: The geographies with a more mobile workforce will be quickest to spread BArelated innovations.

Cost pressures, competition, omni-channel behaviour and regulatory pressures will necessitate the use of external data, and increasingly the protection and control of data. As a significant cost to business, this may regulate the speed of adoption which could well differentiate one company from another in the market. 
In addition to the above traditional TOE factors, our study has found additional factors that have interesting managerial implications.

Business Performance is affected by factors related to the TOE framework. Improvements in business performance can be recognised at the process level whereas the firm level is more difficult to quantify. By highlighting the positive link with performance, this study joins similar studies in the literature (Devaraj et al., 2007; Shin, 2006). Environmental sustainability performance could be included as another outcome variable in addition to business (financial) performance.

Unlike previous studies, there is evidence from our case analysis that the level of adoption and the level of IT integration will influence the link between TOE elements and performance. This implies that firms may benefit from BA better if they take up BA seriously and attempt to integrate BA investments with business strategies. On the other hand, firms that employ a more sluggish approach to adopting BA may be hindered significantly with issues such as legacy systems and may not gain the benefit of BA. Finally, we have found that trust could have a moderating influence on performance, with a higher level of trust improving firm performance.

\subsection{Limitations and scope for future research}

The subjectivity of the self-determination of BA adoption status limited our ability to generalise our conclusions in terms of factors related to level of adoption, because there is no absolute measure of BA adoption against which to compare performance. Most companies compared their adoption to immediate competitors or to specialist service providers. However, the cross section of interviewees provides valuable insight nonetheless. Longitudinal case studies in the future could collect data on BA use over time and provide more convincing evidence demonstrating how the adoption of BA improves firm performance.

We have endeavoured to ensure design validity through defining the case and allowing interviewees to bound their own knowledge for comparison purposes. We used multiple 
sources of evidence (interviews, public domain information, company presentations) and clearly defined the process used for data analysis.

Nine cases provide depth but not breadth. Cases were drawn from retail and the retail supply chain so the results have some generalizability to that sector. However, we invite other academics to test our framework. For example, large scale surveys are needed to offer further validation of our framework, and further in-depth case studies are recommended to test wider validity of our findings in different contexts. 


\section{References}

Al Nahian Riyadh, M., Akter, S., \& Islam, N. (2009). The adoption of e-banking in developing countries: A theoretical model for SMEs. International review of business research papers, 5(6): 212-230.

Armstrong, C. P., and Sambamurthy, V. (1999), "Information technology assimilation in firms: The influence of senior leadership and IT infrastructures", Inform. Systems Res. 10(4) 304-327.

Ashurst, C., Freer, A., Ekdahl, J., \& Gibbons, C. (2012), "Exploring IT-enabled innovation: A new paradigm?", International Journal of Information Management,32(4), 326-336.

Awa, H. O., Ojiabo, O. U., \& Emecheta, B. C. (2015). Integrating TAM, TPB and TOE frameworks and expanding their characteristic constructs for e-commerce adoption by SMEs. Journal of Science and Technology Policy Management, 6(1), 76 - 94.

Baker, J. (2012). The technology-organization-environment framework. In Information systems theory (pp. 231-245). Springer New York.

Barratt, M., Choi, T. Y., \& Li, M. (2011). Qualitative case studies in operations management: Trends, research outcomes, and future research implications. Journal of Operations Management, 29(4), 329-342.

BRC (2012), Data and Stats. 2012 [cited 2012 250612]; stats], British Retail Consortium. Available from: http://www.brc.org.uk/brc_stats_and_facts.asp.

Brundtland, G. H. (1987). Report of the World Commission on environment and development:" our common future.". United Nations.

Brynjolfsson, E. (1993), 'The productivity paradox of information technology', Communications of ACM, vol. 36, no. 12, pp. 66-77.

Chae, B. K. (2015). Insights from hashtag\# supplychain and Twitter analytics: Considering Twitter and Twitter data for supply chain practice and research.International Journal of Production Economics, 165, 247-259.

Chatterjee, D., R. Grewal, and Sambamurthy, V. (2002), "Shaping up for e-commerce: Institutional enablers of the organizational assimilation of Web technologies", MIS Quarterly. 26(2) 65-89.

Chen, H., Chiang, R. H., \& Storey, V. C. (2012). Business Intelligence and Analytics: From Big Data to Big Impact. MIS quarterly, 36(4), 1165-1188.

Childe, S. J. (2011). Case studies in operations management. Production Planning \& Control, 22(2), 107

Chowanetz, M., Legner, C., \& Thiesse, F. (2012). Integration: an omitted variable in information systems research. INTEGRATION, 5, 15-2012.

De Vaus, D. (2002), Surveys in Social Research, Australia, Routledge.

Devaraj, S., Krajewski, L., and Wei, J. C. (2007), „Impact of eBusiness technologies on operational performance: the role of production information integration in the supply chai", Journal of Operations Management, 25(6), 1199-1216.

Ding, J.-H., Chen, P.-S., \& Lyu, J. (2011). Evolutionary strategy to apply information and communication technology: a case study in the apparel industry. Production Planning \& Control, 22(3), 282-297. 
Dreyer, H. C., Strandhagen, J. O., Hvolby, H.-H., Romsdal, A., \& Alfnes, E. (2016). Supply chain strategies for speciality foods: a Norwegian case study. Production Planning \& Control, 27(11), 878-893.

Dubey, R., \& Gunasekaran, A. (2015). Education and training for successful career in Big Data and Business Analytics. Industrial and Commercial Training, 47(4), 174-181.

Eisenhardt, K.M. (1989), "Building theories from case study research", Academy of Management Review 14(4), 532-551

Ghoniem, A., \& Maddah, B. (2015). Integrated retail decisions with multiple selling periods and customer segments: optimization and insights. Omega, 55, 38-52.

Goo, J., Kishore, R., Rao, H.R. and Nam, K. (2009), "The role of service level agreements in relational management of information technology outsourcing: an empirical study", MIS Quarterly, Vol. 33 No. 1, pp. 119-145.

Grover, V., Goslar, M.D., (1993), "The initiation, adoption, and implementation of telecommunications technologies in US organizations", Journal of Management Information Systems 10 (1), 141-163.

Halinen, A. and Tornroos, J. (2005), "Using case methods in the study of contemporary business networks", Journal of Business Research, 58, 1285-1297

Hazen, B. T., Boone, C. A., Ezell, J. D., \& Jones-Farmer, L. A. (2014). Data quality for data science, predictive analytics, and big data in supply chain management: An introduction to the problem and suggestions for research and applications. International Journal of Production Economics, 154, 72-80.

HM Government (2011). A Plan for growth. 2011 [cited 2012 250612].

Hong, W. and K. Zhu (2006), "Migrating to internet-based e-commerce: Factors affecting ecommerce adoption and migration at the firm level", Information \& Management 43 (2006) 204-221.

Hristov, L. and J. Reynolds )2007), Innovation in the UK Retail Sector: report for NESTA, SAID Business School, University of Oxford: Oxford Institute of Retail Management: Oxford.

Hsu, P. F., Ray, S., \& Li-Hsieh, Y. Y. (2014). Examining cloud computing adoption intention, pricing mechanism, and deployment model. International Journal of Information Management, 34(4), 474-488.

Hübner, A. H., \& Kuhn, H. (2012). Retail category management: State-of-the-art review of quantitative research and software applications in assortment and shelf space management. Omega, 40(2), 199-209.

IBM (2011), "From Data to Decisions: the Power of Analytics" IBM Centre for the Business of Government.

Ji-fan Ren, S., Fosso Wamba, S., Akter, S., Dubey, R., \& Childe, S. J. (2016). Modelling quality dynamics, business value and firm performance in a big data analytics environment. International Journal of Production Research, In press, 1-16.

Johnson, J., (1999), "Strategic integration in industrial distribution channels: managing the interfirm relationship as a strategic asset", Journal of the Academy of Marketing Science 27, 4-18. 
Junior, M. L., \& Filho, M. G. (2016). Production planning and control for remanufacturing: exploring characteristics and difficulties with case studies. Production Planning \& Control, 27(3), 212-225.

Ketokivi, M., \& Choi, T. (2014). Renaissance of case research as a scientific method. Journal of Operations Management, 32(5), 232-240.

Krause, D.R., Hanfield, R.B., Scannel, T.V. (1998), “An empirical investigation of supplier development: reactive and strategic processes", Journal of Operations Management 17 (1), 39-58.

Kurnia, S., Karnali, R. J., \& Rahim, M. M. (2015). A qualitative study of business-to-business electronic commerce adoption within the Indonesian grocery industry: a multi-theory perspective. Information \& Management,52(4), 518-536.

Lee, H., and Whang, S. (2001), "Winning the last mile of e-commerce", Sloan Management Review. 42(4) 54-63.

Li, M., Zhao, D., \& Yu, Y. (2015). TOE drivers for cloud transformation: direct or trustmediated?. Asia Pacific Journal of Marketing and Logistics, 27(2), 226-248.

Li, Y.H. (2008), "An empirical investigation on the determinants of e-procurement adoption in chinese manufacturing enterprises", paper presented at 2008 International Conference on Management Science \& Engineering (15th). California, USA.

McKnight, D.H., Cummings, L.L. and Chervany, N.L. (1998), "Initial trust formation in new organizational relationships", Academy of Management Review, Vol. 23 No. 3, pp. 473490.

Mebratu, D. (1998). Sustainability and sustainable development: historical and conceptual review. Environmental impact assessment review, 18(6), 493-520.

Melville, N. P. (2010). Information systems innovation for environmental sustainability. MIS quarterly, 34(1), 1-21

Öberg, C., \& Graham, G. (2016). How smart cities will change supply chain management: a technical viewpoint. Production Planning \& Control, 27(6), 529-538.

Orlitzky, M., Schmidt, F. L., \& Rynes, S. L. (2003). Corporate social and financial performance: A meta-analysis. Organization studies, 24(3), 403-441

Pagell, M., \& Wu, Z. (2009). Building a more complete theory of sustainable supply chain management using case studies of 10 exemplars. Journal of supply chain management, 45(2), 37-56.

Palacios-Marqués, D., Soto-Acosta, P., \& Merigó, J. M. (2015). Analyzing the effects of technological, organizational and competition factors on Web knowledge exchange in SMEs. Telematics and Informatics, 32(1), 23-32.

Peters, R. (2012), The Social Media Marketing Handbook - Everything you need to know about Social Media Marketing, Emereo Publishing.

Piekkari, R. Plakoyiannaki, E. and Welch, C. (2010), "Good' case research in industrial marketing: Insights from research practice", Industrial Marketing Management, 39, 109117

Popper, K.R., (2002), The Logic of Scientific Discovery, $15^{\text {th }}$ ed, London: Routledge

Porter, M. E. (1985), Competitive Advantage: Creating and Sustaining Superior Performance. Free Press, New York. 
Reinmoeller, P., \& Ansari, S. (2015). The Persistence of a Stigmatised Practice: A Study of Competitive Intelligence. Forthcoming in British Journal of Management.

Richards, L. (2009), Handling Qualitative Data: A Practical Guide, Sage, Los Angeles

Rogers, E. M. (1995). Diffusion of innovations (4th, Ed.) New York: Free Press.

Safavi, N. S., Amini, M., \& Javadinia, S. A. (2014). The Determinant of Adoption of Enterprise Resource Planning for Small and Medium Enterprises in Iran. International Journal of Advanced Research in IT and Engineering (IJARIE), 3(1), 1-8.

Schoenherr, T., \& Speier-Pero, C. (2015). Data science, predictive analytics, and big data in supply chain management: Current state and future potential. Journal of Business Logistics, 36(1), 120-132.

Sethi, V. W. and King, R. (1994). "Development of measures to assess the extent to which an information technology application provides competitive advantage", Management Science. 40(12), 1601-1627.

Shin, N. (2006), 'The impact of information technology on the financial performance of diversified firms', Decision Support Systems, vol. 41, pp. 698-707.

Teo, T.S.H., Ranganathan, C. (2004). "Adopters and non-adopters of business-to-business electronic commerce in Singapore", Information and Management 42 (1), 89-102.

Thong, J. Y. (1999). "An integrated model of information systems adoption in small businesses", Journal of Management Information Systems, 15(4), 187-214.

Tornatzky, L. G., and Fleischer, M. (1990). The process of technological innovation. Lexington, MA: Lexington Books.

Troilo, M., Bouchet, A., Urban, T. L., \& Sutton, W. A. (2016). Perception, reality, and the adoption of business analytics: Evidence from North American professional sport organizations. Omega, 59, 72-83.

Voss, C., Tsikriktis, N., and Frohlich, M., 2002. Case research in operations management. International Journal of Operations \& Production Management, 22 (2), 195-219.

Waller, M. A., \& Fawcett, S. E. (2013). Data science, predictive analytics, and big data: a revolution that will transform supply chain design and management. Journal of Business Logistics, 34(2), 77-84.

Wamba, S. F., Akter, S., Coltman, T., \& WT Ngai, E. (2015). Guest editorial: information technology-enabled supply chain management.Production Planning \& Control, 26(12), 933-944.

Wang, Y. M., Wang, Y. S., and Yang, Y. F. (2010). „Understanding the determinants of RFID adoption in the manufacturing industry", Technological Forecasting \& Social Change, $77,803-815$.

Wiengarten, F. Humphreys, P. Cao, G. and McHugh, M. (2013). "Exploring the Important Role of Organizational Factors in IT Business Value: Taking a Contingency Perspective on the Resource-Based View", International Journal of Management Review, 15(1): 3046.

Yen-Lin Kuo, (2013),"Technology readiness as moderator for construction company performance", Industrial Management \& Data Systems, Vol. 113 Iss 4 pp. 558 - 572

Yin, R.K. (2003). Case Study Research: design and methods, $3^{\text {rd }}$ ed. Thousand Oaks: Sage Publications. 
Yu, W., \& Ramanathan, R. (2015). An empirical examination of stakeholder pressures, green operations practices and environmental performance. International Journal of Production Research, accepted paper available online, DOI:10.1080/00207543.2014.931608.

Zhu, K., Kraemer, K. and Xu, S. (2006). "The Process of Innovation Assimilation by Firms in Different Countries: A Technology Diffusion Perspective on E-Business", Management Science, 52 (10), 1557-1576. 